that they quickly come to a focus, cross, and are dispersed over the retina, so that this membrane is fully illuminated. The

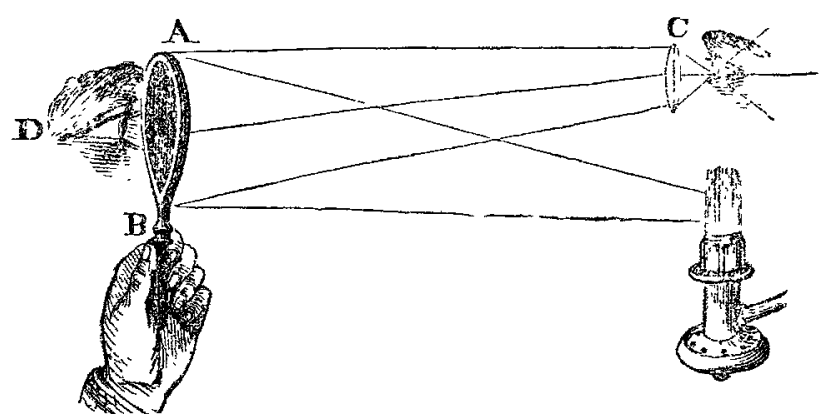

observer's eye at $D$ looks through the small central aperture in the middle of the convex mirror, which he holds in his hand. The patient whose eye is about to be examined, should be taken into a darkened room, and seated by the side of a table, on which is placed an ordinary lamp. The lamp must be brought near the patient's ear, and the flame so arranged that it may be in a straight line with the eye. The observer having taken his seat before the patient, on a stool capable of being raised or lowered. (As a rule it is better to sit a little higher than the patient.) The reflecting surface of the instrument is then to be turned towards the eye to be examined, in such a way, that the eye of the observer, when looking through the small central hole, may see, upon turning the instrument a little inwards, a laminous reflection of the interior of the patient's eye. On withdrawing it gradually, the reflection grows smaller, until it becomes oblong and very brilliant. It is in this way, or slightly modified according to circumstances, that the alterations in the several structures of the eve are to be observed. In the examination of most eyes we are obliged, for the sake of seeing the changes more clearly, to use a bi-convex lens of about two inches focus. Short-sighted people have an advantage, by being enabled to see clearly without this lens.

There are one or two little practical details which the be ginner will do well to observe. In the first place, during the examination, the right eye (supposing the left to be used in looking through the apparatus in the mirror) must watch the movements of the globe of the patient under examination, and the reflection of the mirror at the same time, to see that it is kept upon the patient's eye. The light should not be too strong; a moderate light enables us to note the appearances without its producing fatigue to the patient. For ordinary examinations, the concave mirror is to be preferred; but when a feeble light only can be borne, or we wish to direct our examination to the changes in the vitreous body, or the anterior part of the lens, then the plane mirror will be found to be the best suited to the purpose. Every examination onght to be begun without using the convex lens. It must not be forgotten that the concentration of a powerful light on the retina, if continued for more than a few seconds, does of itself place the part in an unnatural condition.

Next, with regurd to our dilatation of the pupil with atropine. Although it would be next to impossible to investigate some cases without the use of this agent, yet, as a rule, I use it as little as possible; believing, from its known peculiar power over the iris, that it may produce concestion of the whole of the vessels to such an extent as to seriously embarrass the diagnosis. Atropine, to act on the pupil, must be first absorbed, and then it is said to exert a powerfully paralyzing effect on the third pair ; patients complain of the annoyance caused by such dilatation, which often continues for some days. Should the sight afterwards become worse, then of conrse the surgeon will be blamed, and is said to have caused an aggravation of the disease.

You will find, in the greater number of cases, when the patients are taken into a darkened room, and a moderate lamplight only used) the pupils dilate sufficiently for examination. When the rays reflected from the mirror are first allowed to fall upon the fundus of the eye, a diffused glare only is noticed, but as soon as the proper focus has been attained, - which is known by a whitish circle with ranifying vessels coming into view, when the patient turns the eye slightly inwards, - then this red changes into an orange-red, or a tint of a lighter colour as the case may be. The optic nerve is seen faintly tinged with pink, and from its central papilla emerge the artery and vein of the retina; the arrangenents renerally being, that an artery and vein pass upwards, and a similar pair downwards both sorts of vessels then divide into many branches, which run towards the periphery of the retina.
The red colour, in the healthy eye, varies in tint, and this is governed, as Mr. Cumming pointed out, by the complexion of the individual: in the fair, it is brighter; in the dark, it is more of a yellowish-brown. The redness is owing both to retinal and choroidal vessels, the former being distinctly seen branching on the uniform red field formed by the more vascular choroid, showing through the transparent retina. The arteries are distinguished from the veins by their less breadth and brighter colour. The mode of ramification of these vessels varies somewhat in different persons. The veins lie sometimes under, sometimes over, the arteries, and accompany them, so far as regards the principal branches, more or less in their further course. No vessel of any kind covers the foramen centrale, or yellow spot, at least so far as I have been able to make out. In the examination of all objects lying behind the lens, it must be borne in mind that we are looking through that body, and consequently what we see is magnified. Then, again, by using a magnifying-glass to examine the changes in the retina, or increase the illumination in the interior of the eye, we must allow for the difference in intensity and size of the picture. I more particularly draw attention to this fact, as all $m y$ pictures have been made during examinations with the convex lens, and are thereby about four times larger than in nature.

Before an estimate can be formed of the pathological changes revealed by the ophthalmoscope, it must be evident that the normal picture presented by the background of the eye demands careful study; and the part borne by the different membranes in the production of this picture must be the subject of particular consideration. Great difficulty will at first be experienced in the appreciation of a depression or a prominence, say of the papilla optica, which depends in part on the alterations produced in the light and shade of inverted images, and the difficulty must be increased if a convex lens is used with the perforated mirror. When examining the condition of the crystalline lens, the plane or the concave mirror alone should be employed, and it must be viewed from every distance, and in an obilque position, as well as immediately in front of the paticnt. I have frequently succeeded by such means in discovering opacities, when all other modes of investigation havefailed. On the other hand, many cases prononnced to be incipient cataract, on a more careful inspection of the defect, I have found to proceed from a deeper-seated canse.

A few days since, a mechanic presented himself at the hospital, who had been pronounced amanrotic. No visible change could be detected in the dioptic apparatus by daylight. I examined the eye with the ophthalmoscope, and perceived a grey-coloured central opacity on the posterior capsule of the lens. The retinoid vessels and optic nerve were at first seen with difficulty, but after a little while were made out to be in a normal condition.

It is quite unnecessary for me to $d w e l l$ upon the importance of being able to diagnose with absolute certainty the cataracterous form of disease. It is a question we are all often called upon to decide, and one which not unfrequently is as likely to implicate the character of the medical man as the safety of his patient. It is nevertheless at times very difficult to determine, not only the existence, but the seat of the cataract-to say whether the opacity which is seen, is on the crystalline capsule, in the lens, in the vitreous humour, or depends upon a change of the retina, or of the choroid coat.

In addition to the well-known subjective or physiological indications of this defect of vision, if the aid of the ophthalmoscope be sought, no donbt can arise as to the true character of the disease, or whether the opacity is within or without the crystalline capsule, constituting what is known as true and false cataract. In short, the whole of the anatomical changes arising from disease will be found to form so many objective symptoms for our guidance.

$$
\text { (To be concluded.) }
$$

CANNOT ENLARGEMENT OF THE MIDDLE LOBE OF THE PROSTATE GLAND BE RE. MOVED BY THE LATERAT OPERATION OF LITHOTOMY?

BY GEORGE D. GIBB, M.D., L.R.C.S.I.

Some months ago, I had under my care a case of enlargement of the middle lobe of the prostate gland, which had commenced to produce all the inconveniences and miseries arising. from the obstruction to the flow of urine, from the flapping for- 
wards of the tumour and closing the internal orifice of the ure thra, like a valve, on passing urine. Now it struck me at that time, as well as on many other occasions, that in cases of this peculiar affection, where the poor patient oftentimes suffers greater misery than from the presence of a stone in the bladder, relief might be obtained permanently and effectually, by going through the steps of the lateral operation for stone, and cutting away this middle lobe. I seriously contemplated the propriety of its performance on one of my own patients, and think it as well to throw out the hint to those hospital surgeons who are in the way of giving it a trial

Should the result prove effectual-and I see no reason why a patient should not have as good a chance of recovery as in many cases of stone-then it will be one of the greatest triumphs of the surgical art in modern times. What surgeon will be the first to try it? I am induced to send this short note, from witnessing the operation for stone, at King's College Hospital, this day week by Mr. Fergusson, in which that distinguished surgeon excised the middle lobe of the prostate, besides removing two calculi.

Guildford-street, April, 1857.

\section{A s ithror}

\section{OF THE PRACTICE OF}

\section{MEDICINE AND SURGERY IN THE}

\section{HOSPITALS OF LONDON.}

Nulla est alia pro certo noseendi via, nisi quam plurimas et morborum et dissectionum historias, tam aliorum proprias, collectas habere et inter
secomparare.-Morgagn. De Sed. et Caus. Morb. lib. 14. Procmium.

\section{KING'S COLLEGE HOSPITAL。}

STONE IN THE BLADDER, IN AN ELDERLY MAN, WITH FNLARGEMENT OF THE PROSTATE GLAND ; IITHOTOMY ; REMOVAL OF TWO STONES AND EXCLSION OF THE MUDDLE LOBE OF THE PROSTATE

\section{(Under the care of Mr. Fergusson.)}

WE have, within the past few months, geen several cases of stone at the different hospitals, in which lithotomy was performed; some of them possessed slight features of interest, whilst others, again, did not differ in any material point from what is ordinarily met with. Last Saturday, however, a very unusual and striking case presented itself to our notice at this hospital, which demands more than a passing notice at our hands. Every practical surgeon is aware that one of the obstacles to the easy performance of lithotomy as well as lithotrity is enlargement of the prostate. If this enlargement is considerable, it is sometimes a cause of difficulty and annoyance in inexperienced hands. But with the most experienced it often interferes with the process of laying hold of the stone. On this important point $\mathrm{Mr}$. Coulson remarks, in his work on Iithotomy: "But the great obstacle which considerable enlargement of the prostate causes, is to seizing the stone. I places the calculus beyond the reach of the finger, and a sure guide to the position of the foreign body in the bladder is thu lost; while the distance of the vesical cavity from the external surface is greatly increased. Besides this, the enlarged gland, raising up with it the neck of the bladder, leaves behind it a depression or artificial cavity, in which the stone becomes lodged, and easily escapes being detected by the sound or seized with the forceps." - p. 194

Mr. Fergusson's patient was the analogue of this peculiarity; he was a stont, florid, healthy-looking man, aged fifty-nin years, the subject of stone for some years, who had been sent, ten days before, from the country, with some symptoms of disease of the bladder, especially great irritability. A stone was detected, and some enlargement of the prostate gland. It was determined to relieve him by the operation of lithotomy, as it was believed that lithotrity would produce more suffering, from the irritable state of the bladder, and at the same time the fragments could not be easily broken, from the state of the prostate. Moreover, it was suspected that there was more than one stone.
Accordingly, on the 11 th inst., the man was brought into the theatre, and given the vapour of amylene, when Mr. Fergusson proceeded to perform his usual operation. Before doing so, as is his custom, he passed a staff into the bladder, to make sure of the presence of the stone; he failed to touch it; he then passed in a short sound, and readily detected it. Having com. pleted the operation up to the point when his left fortinger was in the bladder, he withdrew his finger, and introduced the forceps. The gush of urine took place, but the stone did not tumble within their jaws, as we have often seen in Mr. Fergusson's operations. Hedid not catch the stone in his usual manner, it eluded his grasp, and he could not get it. It lay in a hollow behind the enlarged middle lobe of the prostate, which formed an obstacle to its being seized with the forceps. He, however, succeeded in removing two irregular-shaped calculi from this hollow, with sharp angles, and of a blackish colour. He then introduced a pair of small stone forceps, laid hold of the pro. jecting lobe of the prostate, and cut it off on a level with the veru-montanum, with a probe-pointed bistoury. This lobe was the size of a small walnut, and had an ulcerated fungus at its apex. The rectum was then injected with some lard and opium, and the patient was removed to his bed, very little blood, indeed, having been lost at the operation, which from first to last did not occupy any longer time than in any other of Mr. Fergusson's cases.

In some observations which were then made, he stated that the present was one of the most remarkable cases which had ever occurred to himself, from the obstacle which prevented his first getting the stone, which he described as an unusual enlargement of the middle lobe of the prostate. In the whole course of his experience he had not before met with such an obstruction, the stone lying behind and below it in a sort of pouch or cavity. This accounted for one of the symptoms which had annoyed this man-namely, great difficulty in getting rid of his urine. He believed the prostate caused this, but he was not prepared to find such a large tumour as was here developed. If he had rested content with merely taking out the calculi, the relief would have been only partial, and he thought of doing what had never been done before, and that was to cut away the middle lobe. He had on several occasions, he said, taken away a portion of the prostate which had projected through the wound. But here the prostate was prominent, not lacerated, and it struck him it would be as well to remove it, which he did quite readily with a small stone forceps, and a probe-pointed bistoury. This, of course, increases the danger of the patient, but it gives him a chance of future com. fort in the event of recovery. The case was most certainly an isolated one, and it is left for experience to say whether the treatment adopted was a correct proceeding.

\section{ST. GEORGE'S HOSPITAL.}

LARGE STONE, THE SIZE OF A FOWL'S EGG, IN THE BLADDER OF A MAN AGLD SIXTY-SIX YEARS; ITTHOTOMY; RECOVERY.

(Under the care of Mr. TATuM.)

ON the 6th of March, we were present when Mr. Tatum performed lithotomy upon a man aged sixty-six years, who had been the subject of stone the last six or seven years, the nuclens of which was supposed to depend upon a renal calculus, from the nature of his early symptoms. An attempt was made to crush the stone in February, but it was found that it was of large size, and very hard, and therefore lithotrity was out of the question. Previous to this, he had been subject to attacks of diarrhœa, which produced great prostration, restless. ness, and much irritability of the bladder.

His general health having become improved by generous diet and tonic treatment, he was submitted to operation, and a lithic-acid calcuIus, somewhat flattened, the size of a fowl's egg, was extracted. Its size rendered this proceeding a little difficult, but by slow and gradual extension the parts yielded sufficiently to permit it to be withdrawn, having been caught in its long diameter. There was free hæmorrhage, but it was controlled after a while by plugging with bits of sponge. There was no enlargement of the prostate in this case, notwithstanding the patient's age, thus forming a striking contrast to Mr. Fergusson's patient. With the exception of threatened peritonitis the following day, we are happy to say the patient has progressed without a bad symptom, and is going about the ward otherwise perfectly well.

On the 29th of January, we saw lithotomy performed by Mr. Pollock on a child two years and a half old, under the in. fluence of amylene, administered by Dr. Snow; and, on the 26 th of February, the same operation, by Mr. H. C. Johnson 